\title{
Predictive value of obsessive-compulsive drinking scale (OCDS) for outcome in alcohol-dependent inpatients: results of a 24-month follow-up study
}

Peggy Schmidt ${ }^{1}$, Claudia Helten ${ }^{1}$ and Michael Soyka ${ }^{1,2^{*}}$

\begin{abstract}
Background: The present study examined whether craving as measured by the obsessive-compulsive drinking scale (OCDS) predict long-term outcome in alcohol-dependent inpatients.
\end{abstract}

Methods: This was a 24-month prospective, observational study in 198 alcohol-dependent inpatients treated under standardized conditions. The primary outcome criterion was abstinence, defined as no subjective report or objective indication of alcohol consumption since discharge from treatment. The patients self-rated their craving for alcohol at the 6- and 12-month follow-ups by using the German version of the OCDS, which measures obsessive and compulsive aspects of craving. Univariate and logistic regression analyses with covariates were performed.

Results: Of the 104 patients interviewed at the 24-month follow-up, 60\% $(n=62)$ were abstinent. We found significant associations between total OCDS scores at 6 months and outcome at 12 months and between total OCDS scores at 12 months and outcome at 24 months: the higher the OCDS total score at one follow-up evaluation, the less likely patients were to be abstinent at the subsequent one. The same association was found for each of the two OCDS subscales, control and consequences and drinking obsessions.

Conclusions: These results support earlier findings that OCDS scores can predict outcome in alcohol-dependent patients. This information can be used for the timely development of protective resources. Hence, decisions over the use of resources can be made on the basis of objectified parameters to develop a personalized treatment concept. Consequently, economic considerations can induce a reduction of high medical costs.

Keywords: Treatment, alcohol, alcoholism, craving, OCDS, outcome

\section{Background}

Craving is a multidimensional construct that has both positive and negative reinforcement properties and plays a key role in relapse to alcohol consumption. It comprises thoughts about alcohol and urges to drink alcohol and is associated with negative affect, depressed mood, distress or withdrawal symptoms (for review see Abrams) [1-7]. There is plethora of research on different forms of craving in substance use disorders [8-12], with some studies indicating that subjective craving is predictive of treatment outcome [13-19]. Patients in remission

\footnotetext{
* Correspondence: michael.soyka@pm-klinik.ch

'Psychiatric Hospital, Ludwig-Maximilians-University, Nußbaumstr. 7, 80336 Munich, Germany

Full list of author information is available at the end of the article
}

are particularly prone to alcohol-related cues or stress that may induce craving [20-23].

The obsessive-compulsive drinking scale (OCDS) [24] is the most widely used multi-factorial self-rated craving scale in alcohol research and treatment. The OCDS measures various aspects of craving for alcohol, including the compulsive urge to drink alcohol, continuous thoughts about alcohol and the struggle to control the urgency. The scale is a modified version of the YaleBrown Obsessive Compulsive Scale [25,26] and aims to measure both obsessive and compulsive aspects of craving. The 14 items of the scale are divided into two subscales, control and consequences (CC) and drinking obsessions (DO). The OCDS has been shown to be a valid self-rated instrument with good test-retest

\section{Biomed Central}


reliability and internal consistence [24,27]. There are several validated translations with good reliability and construct validity, including a German version [6,28-31]. The studies that examined the construct, concurrent and discriminate validity of the OCDS [24,27,32-35] were reviewed by Connor et al. [36], who also performed a further validation study and reported that neither the factor scores nor the total OCDS score was related to baseline alcohol problems or consumption.

The predictive value of OCDS scores for treatment outcome has been demonstrated in some but not all previous studies $[37,38]$ and needs further confirmation [35]. Our goal was to examine the association between OCDS scores and outcome in a sample of alcoholdependent inpatients treated under standardized conditions.

\section{Methods \\ Subjects}

The subjects were 198 alcohol-dependent inpatients. From January to December 2003, all patients admitted to the inpatient clinic AHG Clinic Wilhelmsheim, Germany for treatment of alcohol dependence were consecutively recruited into the study at the start of their treatment. The primary study inclusion criterion was an ICD-10 and DSM-IV diagnosis of alcohol dependence. Exclusion criteria were dependence on benzodiazepines or illicit drugs or both, severe physical illness and severe psychiatric disorders such as psychosis or acute suicidality. All patients who entered treatment participated in the study and all gave written informed consent to participate. The study protocol was approved by the local ethics committee, and the study was performed according to the principles laid down in the Declaration of Helsinki.

Patients received a standard alcohol treatment, which lasted for either 8 weeks (for less severe cases) or 12 to 16 weeks (for more severe cases). The treatment includes both psychoanalytical and behavioural approaches and methods. The treatment concept at the clinic follows an abstinence-oriented approach.

\section{Assessments}

This was a prospective, 24-month follow-up study that measured outcome, defined as abstinence.

Assessments of diagnostic criteria for disorders according to DSM-IV and ICD-10 were made by the Munich Composite International Diagnostic Interview $[39,40]$. Further variables relevant for the analyses were recorded in structured, face-to-face interviews at the start of the programme (Baseline, T0), at discharge from the treatment unit (T1), and at the 6-month (T2), 12-month (T3) and 24-month (T4) follow-ups. The baseline assessment included demographic variables, past and current psychiatric, medical and substance use-related problems, and drinking parameters. Patients were asked about prior detoxifications, prior alcohol rehabilitation and prior treatments for psychiatric problems, except for alcohol dependence. At discharge, the length of time spent in the programme, mode of discharge from the programme (e.g. successfully completed the programme, left prematurely by choice), and relapses during treatment were recorded. Alcohol consumption was reported using the Timeline Followback interview. Patients completed the German version of the OCDS [31] at T2 and T3.

The interviewers were trained psychologists, physicians and medical students and were not involved in the treatment of interviewed subjects; the project coordinator was not a member of the clinical staff. But, the interviewers as well as the project coordinator were in contact with the therapists. For further details see Soyka and Schmidt [41].

Table 1 summarizes the variables, assessment instruments and assessment times.

\section{Definition of outcome criterion}

The primary outcome criterion was abstinence 6,12 and 24 months after discharge from treatment. Abstinence was defined according to the definition from Feuerlein and Kuefner [42] as no subjective report or objective indication of alcohol consumption since discharge. This criterion was used as the dependent variable in the data analyses.

For data analysis, patients were divided into two groups: those who were personally interviewed at the 24-month follow-up and those who did not attend the 24-month follow-up interview.

\section{Data analysis}

Statistical analyses were performed using SPSS for Windows [43].

Absolute and relative frequencies, means and standard deviations (SD) were calculated for data description. Univariate comparisons of responders and non-responders were performed by using the likelihood ratio statistic (for alternative and categorial data), the MannWhitney U test (for ordinal data), and the KolmogorovSmirnov test (for metric data). The predictive value of the OCDS scores was analyzed with logistic regression analyses. The variables which differed between responders and non-responders were inserted as covariates.

All statistical tests were two tailed. A $p$ value of less than 0.05 was considered to be statistically significant. We performed one analysis that only included the data of patients who were personally interviewed at the 24month follow-up and another that also included the data from those who did not attend the 24-month 
Table 1 Variables, assessment instruments and assessment times

\begin{tabular}{ccccc}
\hline T0 & T1 & T2 & T3 & T4 \\
\hline Treatment start & At discharge & 6 months after discharge & 12 months after discharge & 24 months after discharge \\
\hline EuropASI/ patient files: & EuropASI/ & Total abstinence during the & Total abstinence during the & Total abstinence during the \\
Demographics & patient files: & 6 months & 12 months & months \\
Psychiatric, medical and substance & Time in & Re problems & Relapse & Relapse \\
Drinking parameters & $\begin{array}{c}\text { treatment } \\
\text { Mode of } \\
\text { discharge }\end{array}$ & & & OCDS \\
\hline
\end{tabular}

interview; we repeated these two analyses after applying the OCDS modification for longitudinal studies to the data (see Nakovics et al. for further details [44]), making a total of four sets of analyses. There were no significant differences between the results of these four sets of analyses.

\section{Results}

\section{Subject characteristics and outcome}

The subject characteristics are summarized in table 2 . One hundred and ninety-eight patients were enrolled in the study and 104 patients attended the 24-month follow-up. At admission, the mean age of the patients was $45.6(S D=7.4)$ years. The average duration of alcohol dependence was 11.4 ( $S D=8.1)$ years, and the mean age of onset of alcohol dependence 34.0 years $(S D=9.1)$.

Of the patients interviewed at the 24-month follow-up (T4; $n=104), 72 \%(n=75)$ had been continuously abstinent until 6 months after treatment discharge (T2), $67 \%(n=70)$ until the 12-month follow-up (T3), and $60 \%(n=62)$ until T4. There are no significant differences in the baseline and T1 characteristics between the 94 patients who did not attend the 24-month follow up and the 104 patients who attended this follow up.

Significant differences were found at T4 between abstinent $(n=62)$ and non-abstinent patients $(n=42)$ for employment status: 42 (97.7\%) of the patients abstinent at T4 were employed at T0 but only 23 (55\%) of the non-abstinent patients. Furthermore, the non-abstainers had participated in more previous alcohol detoxifications and more previous alcohol rehabilitations than the abstainers. The non-abstainers had repeated alcohol relapses during the treatment period, and more patients of this group dropped out.

\section{Association between the OCDS scores and outcome}

As to be seen in figures 1 and 2, associations were found between the OCDS scores at T2 and outcome at T3 as well as between the scores at T3 and outcome at T4 for both OCDS subscales and the total OCDS score. The mean 6-month OCDS scores of patients abstinent or non-abstinent at T3 were as follows: 1.3 in abstainers vs. 4.1 in non-abstainers $(O R=0.8, p<.05,95 \% \mathrm{CI}=$ $0.7,0.9)$ in the CC subscore; 0.8 in abstainers vs. 2.6 in non-abstainers $(O R=0.8, p<.01,95 \% \mathrm{CI}=0.6,0.9)$ in the DO subscore; and 2.1 in abstainers and 6.7 in nonabstainers $(O R=0.8, p<.01,95 \% \mathrm{CI}=0.7,0.9)$ in the total score. The mean 12-month OCDS scores of patients abstinent or non-abstinent at T4 were as follows: 1.4 in abstainers vs. 4 in non-abstainers $(O R=0.8$, $p<.05,95 \% \mathrm{CI}=0.7,0.9)$ in the CC subscore; 0.9 (abstainers) vs. 2.5 (non-abstainers) in the DO subscore $(O R=0.8, p<.05,95 \% \mathrm{CI}=0.6,0.9)$; and 2.1 (abstainers) vs. 6.7 (non-abstainers) in the total score $(O R=$ $0.8, p<.05,95 \% \mathrm{CI}=0.7,0.9)$.

\section{Discussion}

Our findings indicate that in alcohol-dependent inpatients being treated under standardized conditions in a specialized alcohol inpatient facility, OCDS scores 6 months after discharge are predictive for the 12-month outcome and OCDS scores 12 months after discharge are predictive for the 24-month outcome. Concerning significant results in both subscales, it seems that obsessions as well as control/consequences about alcohol are connected closely with alcohol relapse.

Our findings are in line with other studies reporting that the magnitude of craving is predictive for drinking outcome in alcohol-dependent patients $[17,27,35,37,45,46]$.

Richardson et al [17] randomized 169 patients (70 male, mean age 45) who were treated across three outpatient clinics in Sydney, Australia to receive acamprosate, naltrexone or placebo. They found craving to be a significant predictor of daily drinking during treatment in independence of baseline depression and dependence severity.

Anton et al [27] assessed 41 alcohol-dependent individuals weekly with the OCDS during a 12-week pharmacologic and cognitive-behavioural treatment. The OCDS total and the subscale scores were significantly higher in subjects who had relapsed during the time after the assessment.

Roberts et al [35] studied 132 alcohol dependent patients seeking outpatient treatment. Patients received 
Table 2 Baseline and T1 characteristics of subjects - shown for the total sample and according to drinking status (abstinent or non-abstinent) at the 24-month follow-up (T4)

\begin{tabular}{|c|c|c|c|c|}
\hline & \multirow{2}{*}{$\begin{array}{c}\begin{array}{c}\text { Total } \\
\text { sample }\end{array} \\
(n=104)\end{array}$} & \multicolumn{2}{|c|}{ Patients who responded at $\mathrm{T} 4$} & \multirow{2}{*}{$\begin{array}{c}\text { Difference abstinent vs. non- } \\
\text { abstinent }\end{array}$} \\
\hline & & $\begin{array}{c}\text { abstinent at } \mathrm{T} 4(n= \\
62)\end{array}$ & $\begin{array}{c}\text { non-abstinent at } \mathrm{T} 4(n= \\
42)\end{array}$ & \\
\hline \multicolumn{5}{|l|}{ Baseline } \\
\hline Age $(M, S D)$ & $45.6(7.4)$ & $46.2(7.4)$ & $44.7(7.4)$ & $Z=0.6 ; p=0.93^{a}$ \\
\hline $\operatorname{Sex}(n, \%)$ & & & & $\operatorname{LR}(1, n=104)=0.8 ; p=0.38^{b}$ \\
\hline Male & $77(74)$ & $44(71)$ & $33(79)$ & \\
\hline Female & $27(26)$ & $18(29)$ & $9(21)$ & \\
\hline $\begin{array}{l}\text { Without secondary school qualifications ( } n \text {, } \\
\% \text { ) }\end{array}$ & $3(3)$ & $2(3)$ & $1(2)$ & $\operatorname{LR}(1, n=104)=2.3 ; p=0.80^{b}$ \\
\hline Without professional training $(n, \%)$ & $29(28)$ & $17(27)$ & $12(29)$ & $\operatorname{LR}(1, n=104)=4.3 ; p=0.37^{b}$ \\
\hline Employment status ( $n, \%)$ & & & & $\operatorname{LR}(4, n=104)=9.7 ; p=0.05^{* b}$ \\
\hline Employed & $65(63)$ & $42(68)$ & $23(55)$ & \\
\hline Unemployed & $35(34)$ & $16(26)$ & $19(45)$ & \\
\hline Retired & $4(4)$ & $4(7)$ & 0 & \\
\hline Residential situation ( $n, \%)$ : Living ... & & & & $\operatorname{LR}(5, \mathrm{n}=104)=10.5 ; \mathrm{p}=0.61^{\mathrm{b}}$ \\
\hline alone & $35(34)$ & $15(24)$ & $20(48)$ & \\
\hline with parents & $4(4)$ & $1(2)$ & $3(7)$ & \\
\hline with children & $5(5)$ & $4(7)$ & $1(2)$ & \\
\hline $\begin{array}{l}\text { with cohabitant and with/without } \\
\text { children }\end{array}$ & $59(57)$ & $41(66)$ & $18(43)$ & \\
\hline with friends & $1(1)$ & $1(2)$ & 0 & \\
\hline Marital status ( $n, \%)$ & & & & $\operatorname{LR}(5, n=104)=8.4 ; p=0.14^{b}$ \\
\hline Single & $21(20)$ & $10(16)$ & $11(26)$ & \\
\hline Married & $47(45)$ & $32(52)$ & $15(36)$ & \\
\hline Separated & $5(5)$ & $2(3)$ & $3(7)$ & \\
\hline Divorced & $27(26)$ & $14(23)$ & $13(31)$ & \\
\hline Widowed & $4(4)$ & $4(7)$ & 0 & \\
\hline Age of onset of alcohol use (years: $M, S D$ ) & $15.1(3.9)$ & $15.3(4.3)$ & $14.8(3.3)$ & $Z=0.5 ; p=0.97^{a}$ \\
\hline $\begin{array}{l}\text { Age of onset of regular alcohol use (years: } M \text {, } \\
\text { SD) }\end{array}$ & $22.4(7.3)$ & $22.8(7.4)$ & $21.9(7.2)$ & $Z=0.7 ; p=0.78^{a}$ \\
\hline $\begin{array}{l}\text { Age of onset of alcohol dependence (years: } \\
M, S D \text { ) }\end{array}$ & $34.0(9.1)$ & $34.7(9.3)$ & $32.9(8.8)$ & $Z=0.8 ; p=0.54^{a}$ \\
\hline $\begin{array}{l}\text { Duration of alcohol dependence (years: } M \text {, } \\
\text { SD) }\end{array}$ & $11.4(8.1)$ & $11.5(8.8)$ & $11.2(7.0)$ & $Z=1.1 ; p=0.63^{a}$ \\
\hline Daily alcohol intake (g/day: $M, S D)$ & $176.8(140.7)$ & $156.0(101.9)$ & $207.5(180.8)$ & $Z=0.8 ; p=0.19^{a}$ \\
\hline \multicolumn{5}{|l|}{$\begin{array}{l}\text { Number of previous treatments }(M, S D) \text { for } \\
\text { alcohol }\end{array}$} \\
\hline detoxification & 3.7 (8.6) & $2.9(8.4)$ & $4.7(9.0)$ & $U=996.5 ; p=0.03^{* c}$ \\
\hline rehabilitation & $0.2(0.5)$ & $0.1(0.2)$ & $0.4(0.7)$ & $U=1006.0 ; p=0.002^{* * c}$ \\
\hline psychiatric problems & $1.3(6.1)$ & $0.9(4.6)$ & $1.9(8.0)$ & $U=1266.5 ; p=0.75^{c}$ \\
\hline medical problems & $3.3(3.0)$ & $2.8(1.9)$ & $4.0(4.1)$ & $U=1160.0 ; p=0.34^{c}$ \\
\hline \multicolumn{5}{|l|}{ T1 } \\
\hline $\begin{array}{l}\text { Repeated alcohol relapse during treatment } \\
(n, \%)\end{array}$ & $4(4)$ & 0 & $4(10)$ & $\operatorname{LR}(1, n=104)=7.5 ; p=0.01 * * b$ \\
\hline Treatment drop out $(n, \%)$ & $9(9)$ & 2 (3) & $7(17)$ & $\operatorname{LR}(1, n=104)=5.7 ; p=0.03^{* b}$ \\
\hline
\end{tabular}

${ }^{a}$ Kolmogorov-Smirnov test, ${ }^{b}$ Likelihood ratio statistic, ${ }^{c}$ Mann-Whitney $\mathrm{U}$ test.

${ }^{*} p<0.05 ;{ }^{* *} p<0.01$. 


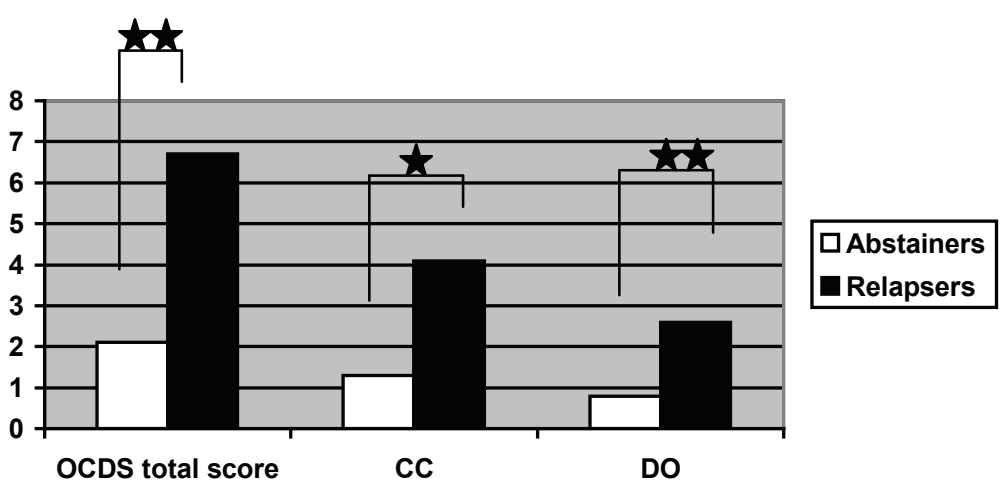

Figure 1 12-month follow-up. Differences in total OCDS score, control and consequences subscore (CC) and drinking obsession subscore (DO) at the 6-month follow-up between patients who were abstainers $(n=62)$ and those who were non-abstainers $(n=42)$ at the 12 -month followup. Logistic regression analyses: 1 . column Wald $=7.0 ; d f=1 ; p=0.012$. column Wald $=6.6 ; d f=1 ; p=0.05$ 3. column Wald $=6.5 ; d f=1 ; p=$ 0.01. ${ }^{*} p<0.05 ;{ }^{* *} p<0.01$.

either $50 \mathrm{mg}$ naltrexone or placebo daily for 12 weeks and attended 12 sessions of cognitive behavioural therapy. The authors suggested the OCDS may better predict shorter term drinking outcomes than prolonged outcomes as each of the OCDS subscale scores predicted the hazard for heavy drinking during the following treatment week.

Bottlender and Soyka [37] reported on 103 patients attended an intensive outpatient treatment program for around 12 month. Patients who relapsed during the treatment phase had significantly higher total OCDS scores as well as higher scores on the subscales 'obsessions' and 'drinking control and consequences' compared to abstinent patients. Furthermore, major relapse was predicted by the total OCDS score and the subscale 'obsessions'.

Gordon et al [45] reported on 218 alcohol-dependent patients admitted to two separate residential addiction treatment programs. They found that days craving reported in the week prior to discharge predicted alcohol use at the three-month follow-up.

Kranzler et al [46] initiated a study with 127 alcohol depended subjects who attended a 12-week outpatient pharmacotherapy trial with a 3-month follow-up period. The predictive validity of the OCDS was not found to be significant but was a tendency.

There is some debate as to whether the OCDS includes questions that may not represent the core concept of craving and therefore requires changes $[29,44,47]$. Still, taken together, our findings suggest that craving as defined and measured by the OCDS items is indeed relevant for predicting long-term outcome in patients. Data from this study further emphasize the role of craving for treatment and outcome in alcohol dependence.

Allocating patients to different treatment settings according to their symptom profile and prediction of

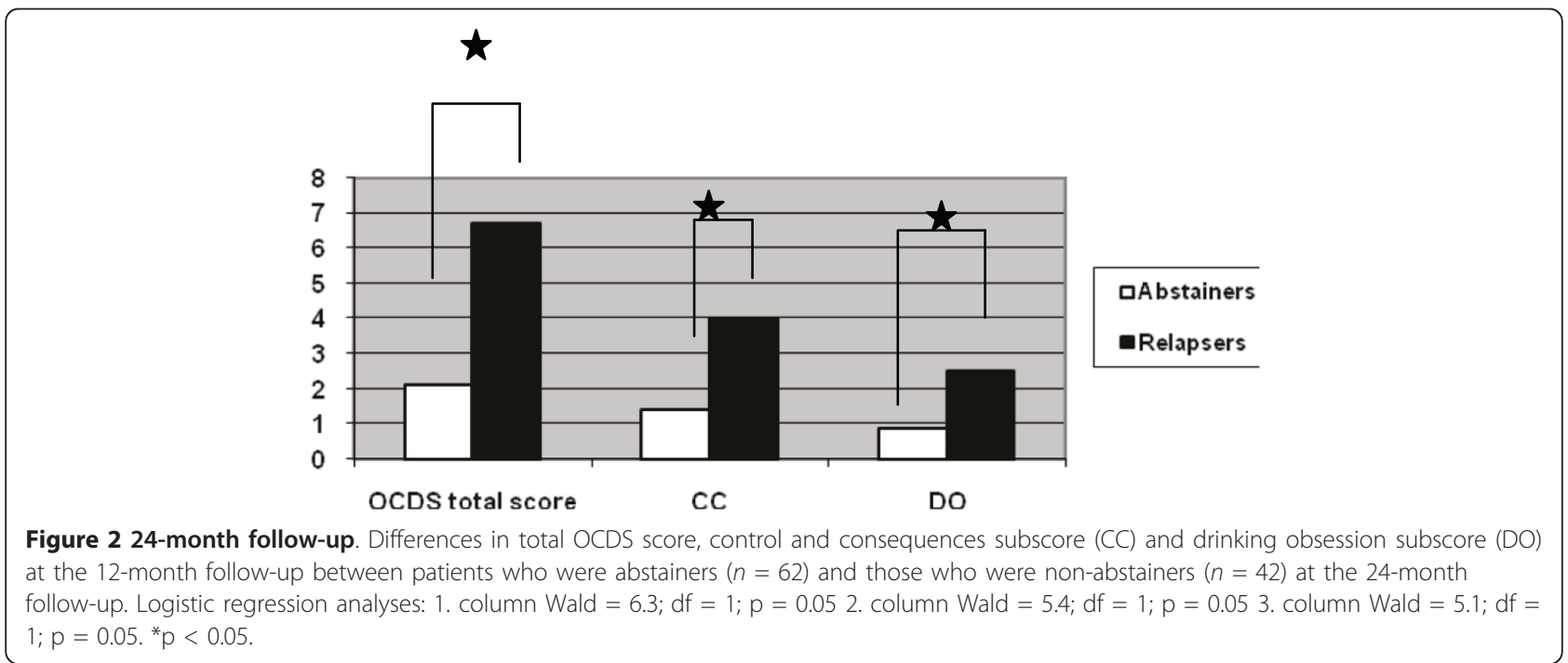


response is a major but difficult clinical task and results of studies are conflicting [48]. Craving has been identified as one of the key symptoms in alcohol dependence and as a major cause of relapse to alcohol $[4,14,34,49]$, craving is similarly relevant in other forms of substance use, especially cocaine $[13,18]$. Craving can be but does not have to be cue related $[12,16,50]$ and can be linked to different positive and negative affective stimuli, cognitive processes and especially stress $[3,7,9,11,51]$. The interrelationship between craving and relapse is unclear and many relapses occur without any clear subjective experience of craving. Still, there is robust evidence for a predictive role of craving for relapse to heavy drinking and many treatment studies use craving scales at least as secondary outcome parameters $[14,16,17,19]$.

The OCDS aims to measure key features of craving [24] and is by far the most frequently used scale in this respect. It was developed on the basis of two theoretical obsessive and compulsive dimensions of alcohol craving $[25,26]$ and is divided into two subscales, obsessions (drinking obsessions; DO) and compulsions (control and consequences; CC). Its predictive value is still a matter of debate $[35,36,38]$. Previously, we demonstrated that the OCDS total score and each of the two subscores are predictive for 12-month follow-up after outpatient treatment for alcohol dependence [37]. Kranzler et al. [46] also demonstrated that a higher OCDS score is predictive for a worse outcome.

There are several limitations to this study. First, no biological markers (such as CDT or GGT) were used to verify outcome and no collateral informants were available. Still, patients were repeatedly seen over a two-year period and personally interviewed, so that the results can be assumed to be reliable. Second, no other craving scales were used to cross-verify results. However, many studies indicate that the OCDS has well to excellent values for validity, as discussed above. As it is another situation if the patients are in treatment compared to the follow up time, we just used the OCDS at time point T2 and T3. Finally, only 104 out of 198 patients who entered inpatient treatment could be followed up by personal interview after 2 years. Nevertheless, this rate is acceptable for follow-up studies in alcoholic patients.

\section{Conclusions}

The results of this study further support that OCDS scores may have predictive value in alcohol-dependent patients and that the OCDS may also be a useful tool in clinical practice to identify patients at risk for relapse. To avoid high follow up costs for further treatments, patients with higher relapse potential are detectable in an earlier stage. The information is useful for the timely development of protective resources. Decisions over the use of resources can be made on the basis of objectified parameters to develop a personalized treatment concept. In this manner, economic considerations can induce a reduction of high medical costs.

\section{Acknowledgements}

The study was funded by the German Pension Fund (Deutsche Rentenversicherung Bund, DRV, Berlin). The authors thank Jacquie Klesing for editing assistance.

\section{Author details}

${ }^{1}$ Psychiatric Hospital, Ludwig-Maximilians-University, Nußbaumstr. 7, 80336 Munich, Germany. ${ }^{2}$ Private Hospital Meiringen, Willingen, 3860 Meiringen, Switzerland

\section{Authors' contributions}

PS performed the statistical analysis and drafted the manuscript. $\mathrm{CH}$ helped to draft the manuscript. MS conceived the study, participated in its design and coordination and helped to draft the manuscript. All authors read and approved the final manuscript.

\section{Competing interests}

The authors declare that they have no competing interests.

Received: 17 February 2011 Accepted: 28 June 2011

Published: 28 June 2011

\section{References}

1. Abrams DB: Transdisciplinary concepts and measures of craving: Commentary and future directions. Addiction 2000, 95(Suppl 2):237-246.

2. Anton RF: Obsessive-compulsive aspects of craving: Development of the Obsessive Compulsive Drinking Scale. Addiction 2000, 95(Suppl 2):211-217

3. Chakravorty S, Kuna ST, Zaharakis N, O'Brien CP, Kampman KM, Oslin D: Covariates of craving in actively drinking alcoholics. Am J Addict 2010, 19:450-457.

4. Flannery BA, Roberts AJ, Cooney N, Swift RM, Anton RF, Rohsenow DJ: The role of craving in alcohol use, dependence, and treatment. Alcohol Clin Exp Res 2001, 25:299-308.

5. Monti PM, Tidey J, Czachowski CL, Grant KA, Rohsenow DJ, Sayette M, Maners N, Pierre P, Building bridges: The transdisciplinary study of craving from the animal laboratory to the lamppost. Alcohol Clin Exp Res 2004, 28:279-287.

6. TatsuzawaY Yoshimasu H, Moriyama Y, Furusawa T, Yoshino A: Validation study of the Japanese version of the Obsessive-Compulsive Drinking Scale. Psychiatry Clin Neurosci 2002, 56:91-95

7. Wietkiewitz K, Bowen S: Depression, craving, and substance use following a randomized trial of mindfulness-based relapse prevention. J Consult Clin Psych 2010, 78:362-374

8. Cherpitel CJ, Borges G, Ye Y, Bond J, Cremonte M, Moskalewicz J, Swiatkiewicz G: Performance of a craving criterion in DSM alcohol use disorders. J Stud Alcohol Drugs 2010, 71:674-684.

9. Field M, Schoenmakers T, Wiers RW: Cognitive processes in alcohol binges: A review and research agenda. Curr Drug Abuse Rev 2008, $1: 263-279$

10. Jimenez M, Grana UL, Montes $V$, Rubio G: Alcohol craving scale based on three factors. Eur Addict Res 2009, 15:135-142.

11. Mason BJ, Light JM, Escher T, Drobes DJ: Effect of positive and negative affective stimuli and beverage cues on measures of craving in non treatment-seeking alcoholics. Psychopharmacology (Berl) 2008, 200:141-150.

12. Ooteman W, Koeter MW, Vserheul R, Schippers GM, Van Den Brink W: Measuring craving: An attempt to connect subjective craving with cue reactivity. Alcohol Clin Exp Res 2006, 30:57-69.

13. Ahmadi J, Kampman KM, Oslin DM, Pettinati HM, Dackis C, Sparkman T: Predictors of treatment outcome in outpatient cocaine and alcohol dependence treatment. Am J Addict 2009, 18:81-6.

14. Flannery BA, Poole SA, Gallop RJ, Volpicelli JR: Alcohol craving predicts drinking during treatment: An analysis of three assessment instruments. J Stud Alcohol Drugs 2003, 64:120-126. 
15. Krampe H, Stawicki S, Ribbe K, Wagner T, Bartels C, Kroener-Herwig B, Ehrenreich $\mathrm{H}$ : Development of an outcome prediction measure for alcoholism therapy by multimodal monitoring of treatment processes. J Psychiatr Res 2008, 43:30-47.

16. Oslin DW, Cary M, Slaymaker V, Colleran C, Blow FC: Daily ratings measures of alcohol craving during an inpatient stay define subtypes of alcohol addiction that predict subsequent risk for resumption of drinking. Drug Alcohol Depend 2009, 103:131-136.

17. Richardson K, Baillie A, Reid S, Morley K, Teesson M, Sannibale C, Weltman M, Haber P: Do Acamprosate or Naltrexone have an effect on daily drinking by reducing craving for alcohol? Addiction 2008, 103:953-959.

18. Rohsenow DJ, Martin RA, Eaton CA, Monti PM: Cocaine craving as a predictor of treatment attrition and outcomes after residential treatment for cocaine dependence. J Stud Alcohol Drugs 2007, 68:641-648.

19. Yoon G, Kim SW, Thuras P, Grant JE, Westermeyer J: Alcohol craving in outpatients with alcohol dependence: Rate and clinical correlates. J Stud Alcohol Drugs 2006, 67:770-777.

20. Breese GR, Chu K, Dayas CV, Funk D, Knapp DJ, Koob GF, Le DA, O'Dell LE, Overstreet DH, Roberts AJ, Sinha R, Valdez GR, Weiss F: Stress enhancement of craving during sobriety: A risk for relapse. Alcohol Clin Exp Res 2005, 29:185-195.

21. Sinha R, Catapano D, O'Malley S: Stress-induced craving and stress response in cocaine dependent individuals. Psychopharmacology (Berlin) 1999, 142:343-351.

22. Sinha R, Fus T, Aubin LR, O'Malley SS: Psychological stress, drug-related cues and cocaine craving. Psychopharmacology (Berlin) 2000, 152:140-148.

23. Sinha R, Garcia M, Paliwal P, Kreek MJ, Rounsaville BJ: Stress-induced cocaine craving and hypothalamic-pituitary-adrenal responses are predictive of cocaine relapse outcomes. Arch Gen Psychiatry 2006, 63:324-331.

24. Anton RF, Moak DH, Latham P: The Obsessive Compulsive Drinking Scale: A self-rated instrument for the quantification of thoughts about alcohol and drinking behavior. Alcohol Clin Exp Res 1995, 19:92-99.

25. Modell JG, Glaser FB, Cyr L, Mountz JM: Obsessive and compulsive characteristics of craving for alcohol in alcohol abuse and dependence. Alcohol Clin Exp Res 1992, 16:272-274.

26. Modell JG, Glaser FB, Mountz JM, Schmaltz S, Cyr L: Obsessive and compulsive characteristics of alcohol abuse and dependence: Quantification by a newly developed questionnaire. Alcohol Clin Exp Res 1992, 16:266-271.

27. Anton RF, Moak DH, Latham PK: The Obsessive Compulsive Drinking Scale: A new method of assessing outcome in alcoholism treatment studies. Arch Gen Psychiatry 1996, 53:225-231.

28. Ansseau M, Besson J, Lejoyeux M, Pinto E, Landry U, Cornes M, Deckers F, Potgieter A, Ades J: A French translation of the Obsessive-Compulsive Drinking Scale for craving in alcohol-dependent patients: A validation study in Belgium, France, and Switzerland. Eur Addict Res 2000, 6:51-56.

29. Cordero M, Solis L, Cordero R, Torruco M, Cruz-Fuentes C: Factor structure and concurrent validity of the Obsessive Compulsive Drinking Scale in a group of alcohol-dependent subjects of Mexico City. Alcohol Clin Exp Res 2009, 33:1145-1150.

30. Janiri L, Calvosa F, Dario T, Ruggeri A, Pozzi G, Addolorato G, De Risio S: The Italian version of the Obsessive-Compulsive Drinking Scale: Validation, comparison with the other versions, and difference between type 1- and type 2-like alcoholics. Drug Alcohol Depend 2004, 74:187-195.

31. Mann K, Ackermann K: Die OCDS-G: Psychometrische Kennwerte der deutschen Version der Obsessive Compulsive Drinking Scale. Sucht 2000, 46:90-100.

32. Bohn MJ, Barton BA, Barron KE: Psychometric properties and validity of the Obsessive-Compulsive Drinking Scale. Alcohol Clin Exp Res 1996, 20:817-823.

33. Moak DH, Anton RF, Latham PK: Further validation of the ObsessiveCompulsive Drinking Scale (OCDS). Relationship to alcoholism severity. Am J Addict 1998, 7:14-23.

34. Potgieter AS, Deckers F, Geerlings P: Craving and relapse measurement in alcoholism. Alcohol Alcohol 1999, 34:254-260.

35. Roberts JS, Anton RF, Latham PK, Moak DH: Factor structure and predictive validity of the Obsessive Compulsive Drinking Scale. Alcohol Clin Exp Res 1999, 23:1484-1491.
36. Connor JP, Jack A, Feeney GF, Young RM: Validity of the Obsessive Compulsive Drinking Scale in a heavy drinking population. Alcohol Clin Exp Res 2008, 32:1067-1073

37. Bottlender M, Soyka M: Impact of craving on alcohol relapse during, and 12 months following, outpatient treatment. Alcohol Alcohol 2004, 39:357-361.

38. Morgan TJ, Morgenstern J, Blanchard KA, Labouvie E, Bux DA: Development of the OCDS-revised: A measure of alcohol and drug urges with outpatient substance abuse clients. Psychol Addict Behav 2004 18:316-321.

39. Wittchen HU, Pfister H: DIA-X-Interview: Manual für Screening-Verfahren und Interview; Interviewheft Längsschnittuntersuchung (DIA-X-Lifetime); Ergänzungsheft (DIA-X-Lifetime); Interviewheft Querschnittuntersuchung (DIA-X-12 Monate); Ergänzungsheft (DIA-X-12 Monate); PC-Programm zur Durchführung des Interviews (Längs- Und Querschnittuntersuchung); Auswertungsprogramm. Frankfurt: Swets \& Zeitlinger; 1997.

40. Wittchen HU, Semler G: Composite International Diagnostic Interview (CIDI, Version 1.0). Weinheim: Beltz; 1991.

41. Soyka M, Schmidt P: Outpatient alcoholism treatment-24-month outcome and predictors of outcome. Subst Abuse Treat Prev Policy 2009, 4:15, serial online.

42. Feuerlein $W$, Kuefner $H$ : A prospective multicentre study of in-patient treatment for alcoholics: 18- and 48-month follow-up (Munich Evaluation For Alcoholism Treatment, MEAT). Eur Arch Psychiatry Neurol Sci 1989, 239:144-157.

43. SPSS Software Company: Statistic Package for Social Science Software. Version 18 SPSS; 2009.

44. Nakovics H, Diehl A, Croissant B, Mann K: Modifications of the Obsessive Compulsive Drinking Scale (OCDS-G) for use in longitudinal studies. Addict Behav 2008, 33:1276-1281.

45. Gordon SM, Sterling R, Siatkowsko C, Raively K, Weinstein S, Hill PC: Inpatients desire to drink as a predictor of relapse to alcohol use following treatment. Am J Addict 2006, 15:242-245.

46. Kranzler HR, Mulgrew CL, Modesto-Lowe V, Burleson JA: Validity of the Obsessive Compulsive Drinking Scale (OCDS): Does craving predict drinking behavior? Alcohol Clin Exp Res 1999, 23:108-14.

47. De Wildt WA, Lehert P, Schippers GM, Nakovics H, Mann K, Van Den Brink W: Investigating the structure of craving using structural equation modeling in analysis of the Obsessive-Compulsive Drinking Scale: A Multinational Study. Alcohol Clin Exp Res 2005, 29:509-516.

48. Adamson SJ, Sellman JD, Frampton CM: Patient predictors of alcohol treatment outcome: A systematic review. J Subst Abuse Treat 2009, 36:75-86.

49. Tiffany ST: Cognitive concepts of craving. Alcohol Res Health 1999, 23:215-224.

50. Drobes DJ, Carter AC, Goldman MS: Alcohol expectancies and reactivity to alcohol-related and affective cues. Exp Clin Psychopharmacol 2009, 17:1-9.

51. Sinha R, Fox HC, Hong KA, Bergquist K, Bhagwagar Z, Siedlarz KM: Enhanced negative emotion and alcohol craving, and altered physiological responses following stress and cue exposure in alcohol dependent individuals. Neuropsychopharmacology 2009, 34:1198-208.

doi:10.1186/1747-597X-6-14

Cite this article as: Schmidt et al:: Predictive value of obsessivecompulsive drinking scale (OCDS) for outcome in alcohol-dependent inpatients: results of a 24-month follow-up study. Substance Abuse Treatment, Prevention, and Policy 2011 6:14. 